\title{
Mathematical Models for the Novel Cathode Convexes in a Reduction Cell
}

\author{
Z. He, T. Xia, W. Xiong, Q. Shen, and B. Li \\ Key Laboratory for Ferrous Metallurgy and Resources Utilization of Ministry of Education, \\ Wuhan University of Science and Technology, Wuhan 430081, China
}

Correspondence should be addressed to Z. He; hezhu@wust.edu.cn

Received 13 December 2012; Revised 22 February 2013; Accepted 8 March 2013

Academic Editor: Seetharaman Sridhar

Copyright (c) 2013 Z. He et al. This is an open access article distributed under the Creative Commons Attribution License, which permits unrestricted use, distribution, and reproduction in any medium, provided the original work is properly cited.

\begin{abstract}
A less magnitude of liquid aluminum deformation is required to shorten the anode-cathode distance so as to lower the electric energy consumption of the aluminum reduction cell. A mathematical model aimed to describe the electrolyte/aluminum twophase flow in reduction cells, based on the computational fluid dynamics method, was developed to study the impacts of the cathode convexes on the electrolyte/aluminum interface deformation. The results showed that the magnitude of the two-phase interface deformation was reduced for about $17.2 \%$ with the novel cathode convexes; while at the same time, the washout of the melt on the ledge was also enhanced.
\end{abstract}

\section{Introduction}

Aluminum and its aluminum material is the second large metal materials in the world whose consumption is only next to the steel. Aluminum metal was produced by the electrolysis of aluminum oxide dissolved in an aluminumelectrolyte fluoride mixture, which requires large amounts of electrical energy. Therefore, there is an urgent demand to lower energy consumption in the process of aluminum production. To decrease the energy consumption, the anodecathode-distance (ACD) in reduction cells needs to be cut down [1]. However, due to the electrolyte/aluminum interface instability, the ACD cannot be too small to avoid reduction cell voltage fluctuation which may result in cell failure [2].

The instability between the layer of molten aluminum and a slightly lighter electrolyte plays a defining role in the energy saving of aluminum reduction cells. Consequently, many researchers have focused on uncovering the mechanism of this instability. By using particle image velocimetry, Cooksey and Yang [3] experimentally investigated the onflow caused by anode gas and its bubble behavior in a full-scale, threeanode liquid model aluminum reduction cell. Pedchenko et al. [4] proposed a new solution for experimental modeling of the interfacial instability in which a tiny electrode stick was immerged into liquid metal of In-Ga-Sn on substitute of molten aluminum overlaid by electrolyte. Due to the difficulty to experimentally study the complex fluid flow phenomenon including molten aluminum, bath, and bubble agitation in aluminum reduction cells, most researchers focused on numerically modeling the magnetic fluid flow in reduction cells. Based on the nonlinear shallow water model, Kadkhodabeigi [5] built up a two dimensional model to study the electrolyte/aluminum interface instability and this model is superior to the linear model because linear model cannot determine the flow mode of the electrolyte and aluminum. Bojarevics and Pericleous [6] presented a nonlinear cell stability analysis for the $500 \mathrm{kA}$ cell based on the shallow water model and showed the cathode surface unevenness and the presence of the anode bottom channels would sharply affect the cell stability. Li et al. [7] developed an improved finite-element model by building the contact mechanisms between steel bars and cathode blocks to make sure the voltage drops are properly distributed in the metal and the cathode. Based on the commercial package Ansys $\mathrm{Li}$ and Zhou [8] investigated the effects of various busbar configuration parameters on the stability of the reduction cell and proposed the improved busbar configuration. Bojarevics and Pericleous [9] proposed a simple shallow water model which allowed account of the channels and the interface stability is tested and compared for the channel effects. 


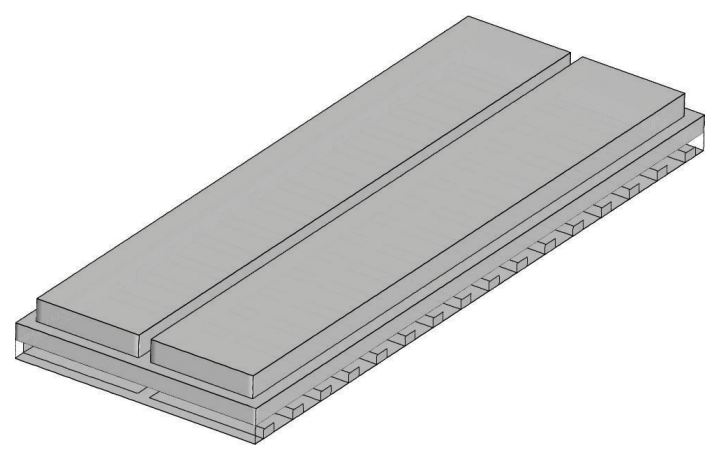

FIGURE 1: Geometry of the reduction cell.

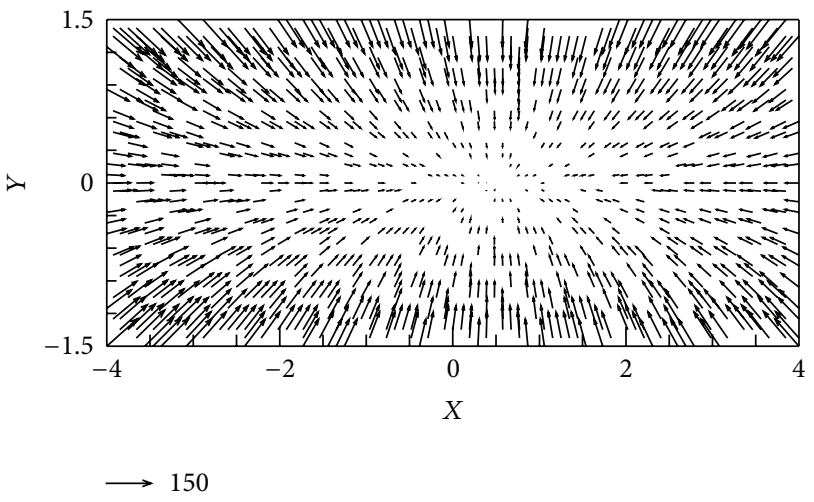

Figure 2: Distribution of the horizontal electric-magnetic force in the middle plane of the liquid aluminum.

In their following studies, Bojarevics and Pericleous [10] extended their model to time dependent case and account for the electrolyte channels. Liu et al. [11] developed a current efficiency predictive model based on multiphase multicomponent flow, which provides a new approach for predicting current efficiency of aluminum reduction cells.

What have been discussed above showed that though many works have been done to investigate the electrolyte/aluminum interface instability, neither reduction cells with inert anode [12] nor drained cathode cells [13] can decrease the energy consumption significantly in industrial scale experiment. Recently a new kind of aluminum reduction cell with novel cathodes has been tested industrially and the results showed that its energy consumption decreased for more than $1200 \mathrm{kWh} / \mathrm{t}-\mathrm{Al}$ when compared with other reduction cells [14]. In the present work, the effects of novel cathode convexes on the interface instability were investigated to provide a theoretical foundation for improving the structure of the novel cathode and energy saving effects.

\section{Numerical Models}

Molten aluminum and electrolyte are treated as incompressible viscous fluid and electromagnetic force is the driving factor for melt to flow. Three dimensional Reynolds Average Navier-Stokes Equation was generally used to solve melt flow. The $k-\varepsilon$ turbulence model coupled with standard wall functions was adopted to account for the turbulence effects

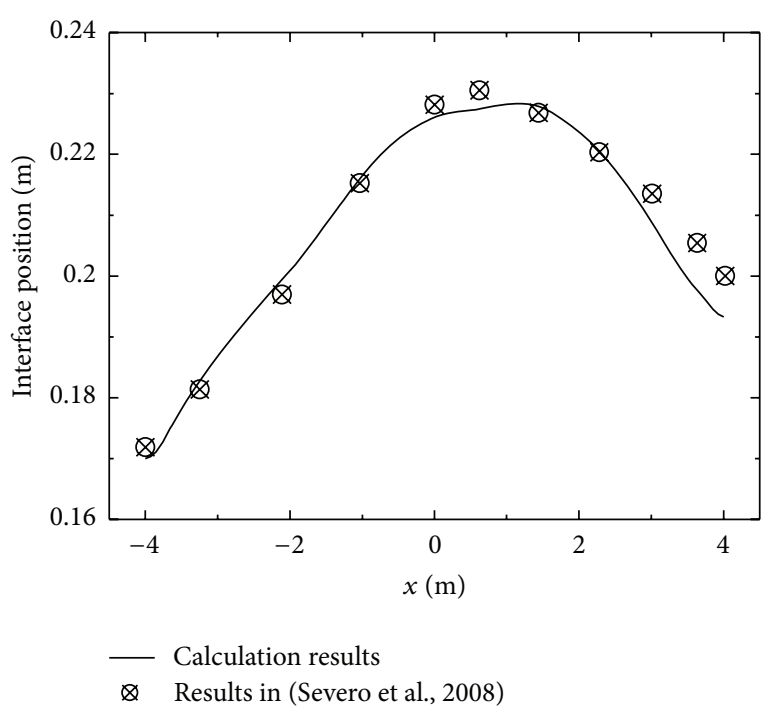

FIgURE 3: Height of the electrolyte/aluminum interface at the middle line.

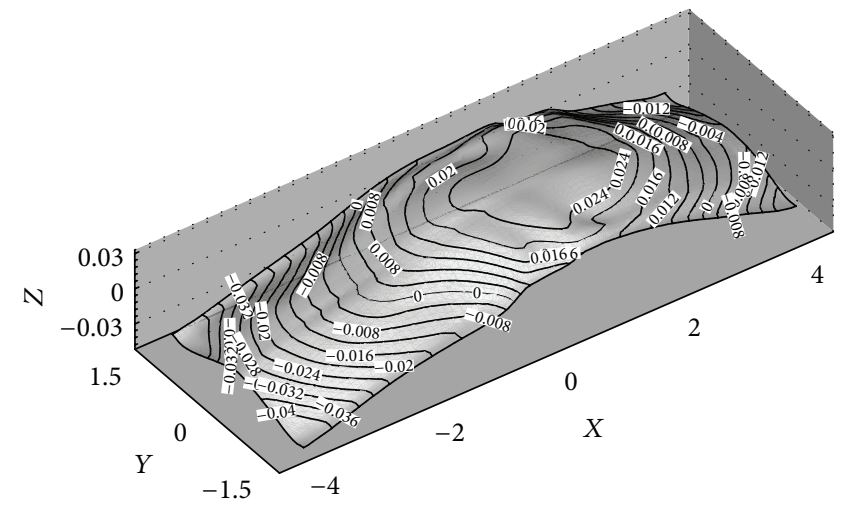

FIGURE 4: Shape of the electrolyte/aluminum interface.

and second order discretization on governing equations was employed to improve the accuracy of the solution. Volume of Fluid (VOF) method was used to compute the aluminum/electrolyte two-phase flow field.

The control equations of the aluminum/electrolyte flow field include the following.

Continuity equation:

$$
\frac{\partial \overline{u_{j}}}{\partial x_{j}}=0 .
$$

Momentum equation:

$$
\begin{aligned}
\rho \frac{\partial \overline{u_{i}}}{\partial t}+\rho \overline{u_{j}} \frac{\partial \overline{u_{i}}}{\partial x_{j}}= & -\frac{\partial \bar{p}}{\partial x_{i}} \\
& +\frac{\partial}{\partial x}\left(\mu_{\mathrm{eff}}\left(\frac{\partial \overline{u_{i}}}{\partial x_{j}}+\frac{\partial \overline{u_{j}}}{\partial x_{x}}\right)\right)+F
\end{aligned}
$$

where $\rho$ is the density, $\overline{u_{i}}$ is the time averaged velocity component, $\bar{p}$ is the time averaged pressure, $\mu_{\mathrm{eff}}$ is the effective 


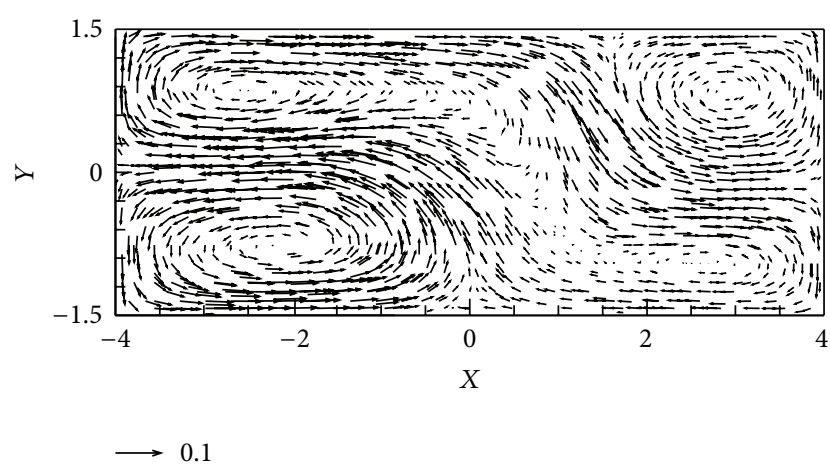

FIGURE 5: Distribution of the horizontal velocity vectors in the middle plane of the liquid aluminum.

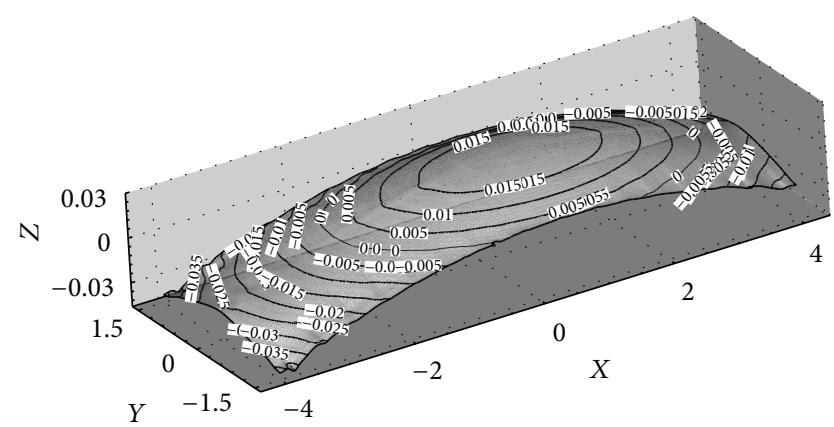

FIGURE 6: Shape of the electrolyte/aluminum interface with cathode convexes.

viscosity, and $F$ is the volumetric force, which includes electromagnetic force $F_{\mathrm{em}}=J \times B$ and gravity $F_{\mathrm{g}}$, respectively.

$k$-equation:

$$
\frac{\partial\left(\rho k u_{i}\right)}{\partial x_{i}}=\frac{\partial}{\partial x_{j}}\left[\left[\mu+\frac{\mu_{t}}{\sigma_{k}}\right] \frac{\partial k}{\partial x_{j}}\right]+G_{k}-\rho \varepsilon
$$

$$
\begin{aligned}
& \text { E-equation: } \\
& \frac{\partial\left(\rho \varepsilon u_{i}\right)}{\partial x_{i}}=\frac{\partial}{\partial x_{j}}\left[\left[\mu+\frac{\mu_{t}}{\sigma_{k}}\right] \frac{\partial \varepsilon}{\partial x_{j}}\right]+\frac{C_{1 \varepsilon} \varepsilon}{k} G_{k}-C_{2 \varepsilon} \rho \frac{\varepsilon^{2}}{k}
\end{aligned}
$$

where $G_{k}$ represents the generation of turbulence kinetic energy due to the mean velocity gradients,

$$
\begin{gathered}
G=\mu_{t} \frac{\partial u_{j}}{\partial x_{i}}\left(\frac{\partial u_{i}}{\partial x_{j}}+\frac{\partial u_{j}}{\partial x_{i}}\right), \\
\mu_{\text {eff }}=\mu+\mu_{t} .
\end{gathered}
$$

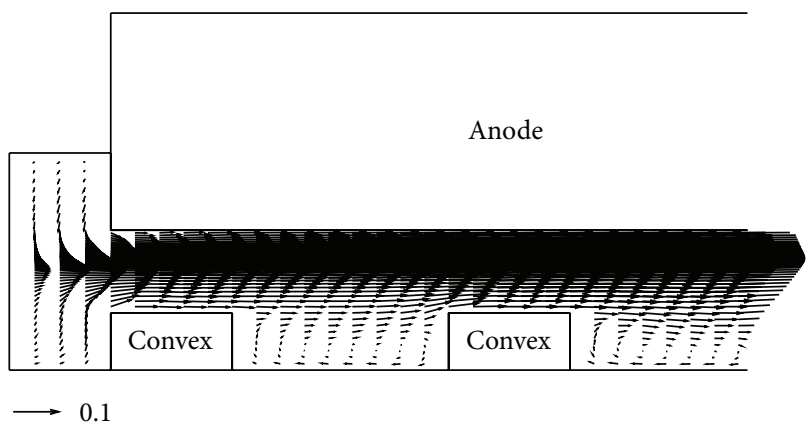

FIGURE 7: Velocity vector distribution at the cross plane $Z X$, with $Y=-1$ (with convexes).

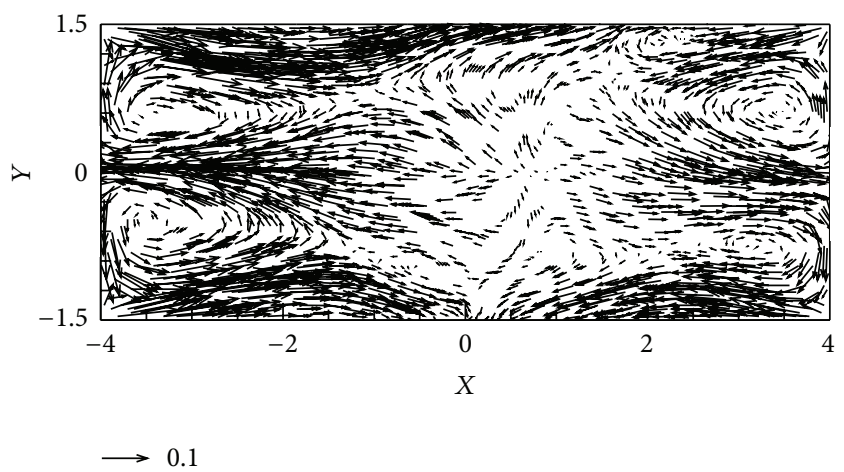

FIGURE 8: Distribution of the horizontal velocity vectors in the middle plane of the liquid aluminum with cathode convexes.

$\mu_{t}$ is turbulent viscosity:

$$
\mu_{t}=\rho C_{\mu} \frac{k^{2}}{\varepsilon} .
$$

The typical constants of the $k-\varepsilon$ model of Launder and Spalding [15] are: $c_{1 \varepsilon}=1.44, c_{2 \varepsilon}=1.92, c_{\mu}=0.09, \sigma_{k}=1.00$, $\sigma_{\varepsilon}=1.30$.

Volume fraction equation:

$$
\begin{gathered}
\frac{\partial \alpha_{q}}{\partial t}+u_{i} \frac{\partial \alpha_{q}}{\partial x_{i}}=0, \\
\sum_{q=1}^{n} \alpha_{q}=1,
\end{gathered}
$$

where $\alpha_{q}$ is the volume fraction of the $q$ th phase, $q=1,2$ represent aluminum and electrolyte, respectively.

The computational model in the present study is the second benchmark case in [16]; its geometry is shown in Figure 1. The computational parameters are listed in Table 1. In this benchmark case, magnetic field and current density distributions are simple analytical expressions, but their shape and magnitude are typical for real cells. No interanode gaps in the longitudinal direction are used.

Firstly, Laplace equation $\Delta V=0$ was solved to get the current density distribution in the reduction cell, where $V$ 

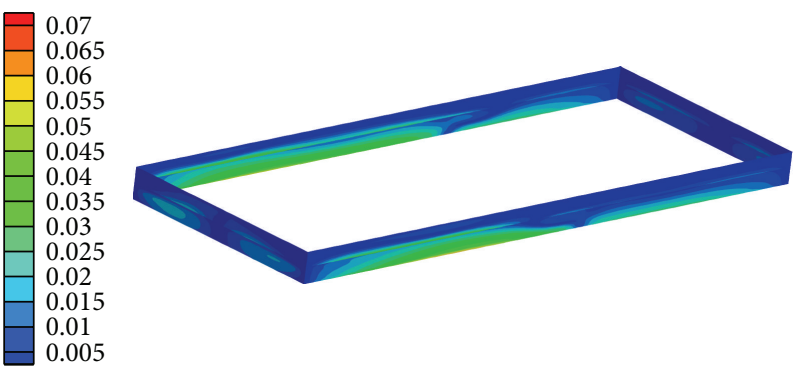

(a) Without cathode convexes
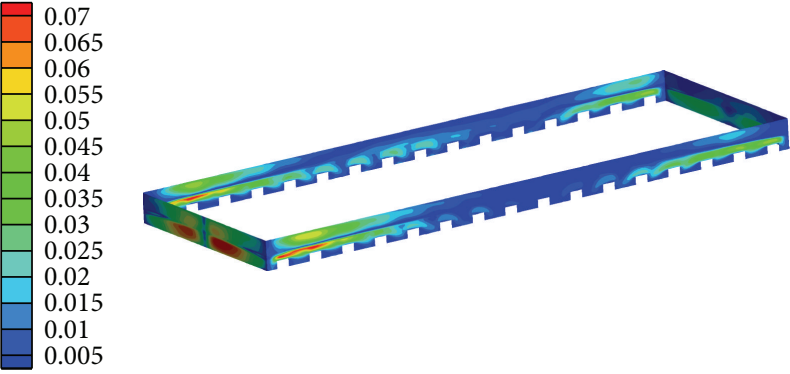

(b) With cathode convexes

FIGURE 9: Wall shear stress distributions.

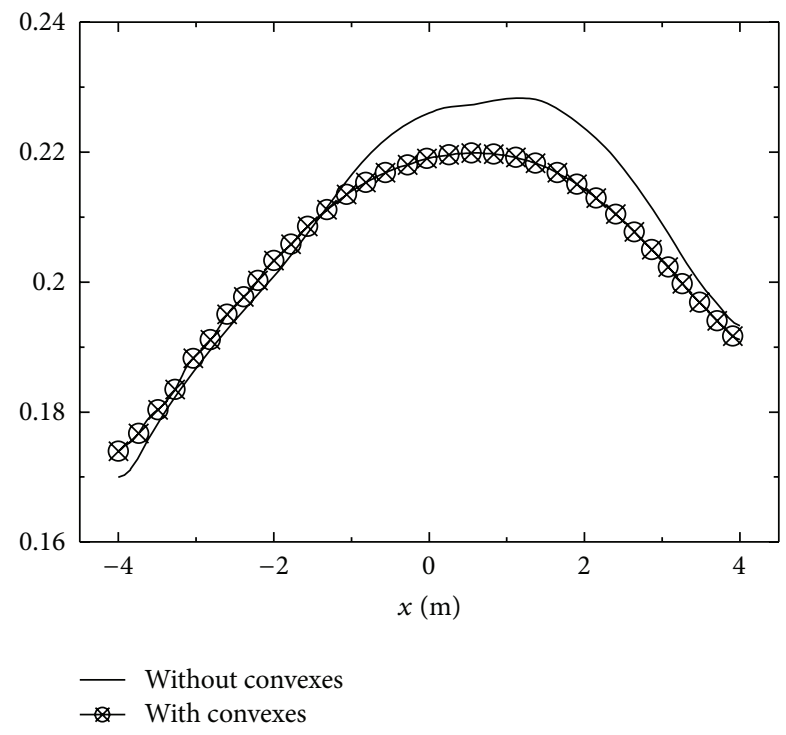

Figure 10: Height of the electrolyte/aluminum interface at the middle line.

TABLE 1: Computational parameters.

\begin{tabular}{lcccc}
\hline $\begin{array}{l}\text { Aluminum } \\
\text { height }\end{array}$ & $\begin{array}{c}\text { Electrolyte } \\
\text { height }\end{array}$ & ACD & $\begin{array}{c}\text { Aluminum } \\
\text { density }\end{array}$ & $\begin{array}{c}\text { Electrolyte } \\
\text { density }\end{array}$ \\
\hline $0.2 \mathrm{~m}$ & $0.18 \mathrm{~m}$ & $0.045 \mathrm{~m}$ & $2270 \mathrm{~kg} / \mathrm{m}^{3}$ & $2070 \mathrm{~kg} / \mathrm{m}^{3}$ \\
\hline
\end{tabular}

is the electrical potential. At the top of the cathode block, the current density is specified as the boundary condition: $J_{z}=-5625-2500 y^{2}\left(\mathrm{~A} / \mathrm{m}^{2}\right)$. At the top of anode blocks, zero electrical potential is specified. The electromagnetic force density fields, which drive the molten aluminum and electrolyte flow, are obtained as vector product of electric current density and magnetic field. The three components of the magnetic field inside the bath and the metal can be gotten in [16]. Electromagnetic force distributions in the middle plane of the molten aluminum are shown in Figure 2.

\section{Results and Discussion}

To validate the present model, the calculated results are compared with those presented in [16], as shown in Figure 3. The interface location is calculated where the volume fraction of the metal and of the bath is 0.5. The results in Figure 3 shows that the predictions of the present model agree well with those in [16] with a deviation not exceeding 5\%, which laid the basis of further investigation. The aluminum/electrolyte interface shape is shown in Figure 4. Under the influence of the electromagnetic force which is the results of the horizontal magnetic field and the vertical electric current, molten aluminum was upheaved in the middle part. The peak uplift amplitude is about $2.4 \mathrm{~cm}$ and the max downwelling amplitude is about $4 \mathrm{~cm}$, which approximately equal to the fluctuation magnitude in real cells. Current efficiency can be further improved by adequate fine adjustment in real reduction cells.

Figure 5 shows the velocity vector distributions in the middle plane of the molten aluminum. Four large vortices are formed in flow field and the size of the left vortex is larger than the right one. The velocity magnitude of the molten aluminum around the left vortex is larger, which makes the washout on the side ledge more severe.

Interface shape of the reduction cell with cathode convexes is shown in Figure 6. Similar to the case without convexes, molten aluminum was upheaved in the middle part, but the upheaval magnitude was weaken evidently when cathode convexes were used in the reduction cell. The peak uplift amplitude is about $1.5 \mathrm{~cm}$ and the max downwelling amplitude is about $3.8 \mathrm{~cm}$. The peak uplift and downwelling amplitude are reduced by $37.5 \%$ and $5 \%$, respectively, and the fluctuation magnitude is reduced by $17.2 \%$.

With the cathode convexes, the magnitude of the electromagnetic force distributions in the middle plane of the molten aluminum is decreased for about $10 \%$, but the distribution is very similar to what is shown in Figure 2 (not shown here). The usage of the cathode convexes brings about the secondary flow of the molten aluminum between the cathode convexes as shown in Figure 7. This secondary flow could also be the reason for weaken interfacial fluctuation magnitude. As a result, the usage of cathode convex makes it possible to further decrease ACD and lower the energy consumption. Figure 8 shows the velocity vector distributions in the middle plane of the molten aluminum when cathode convexes are used. The flow mode of the molten aluminum has been changed greatly when compared with that shown in Figure 5. The washout of the molten aluminum on the side 
ledge is more serious than that in reduction cells without cathode convexes, which can be also observed in Figure 9. The wall shear stress on the side ledge is obviously larger when cathode convexes are used as shown in Figure 9.

Figure 10 compared the interface profile on the longitudinal axis located at the center of the cell with and without convex. It clearly showed the inhibition effects of the cathode convexes on the molten aluminum fluctuation.

\section{Conclusions}

A steady three-dimensional model of the electrolyte/aluminum two-phase flow in reduction cells was developed in the present study, in which time dependent interface motion is not considered. Based on this model electrolyte/aluminum interface fluctuations in the reduction cell with novel cathode convexes were investigated. The results showed that the model is able to represent the flow mode of the electrolyte/aluminum two-phase flow in reduction cells adequately. The model predicted that the magnitude of the twophase interface deformation was reduced for about $17.2 \%$ with novel cathode convexes; while at the same time, the washout of the melt on the ledge was also enhanced.

\section{Acknowledgments}

This work is supported by the National Natural Science Foundation of China (no. 50934005) and the Open Research Fund of Key Laboratory for Ferrous Metallurgy and Resources Utilization of Ministry of Education, Wuhan University of Science and Technology.

\section{References}

[1] Y. Tian, "Discussion on Best Polar Distance of Industrial Aluminum Cell," Non-Ferrous Mining and Metallurgy, vol. 25, pp. 23-25, 2007.

[2] O. Zikanov, A. Thess, P. A. Davidson, and D. P. Ziegler, "A new approach to numerical simulation of melt flows and interface instability in hall-héroult cells," Metallurgical and Materials Transactions B, vol. 31, no. 6, pp. 1541-1550, 2000.

[3] M. A. Cooksey and W. Yang, "PIV measurements on physical models of aluminum reduction cells," in Light Metals, pp. 359365, 2005.

[4] A. Pedchenko, S. Molokov, J. Priede, A. Lukyanov, and P. J. Thomas, "Experimental model of the interfacial instability in aluminium reduction cells," Europhysics Letters, vol. 88, no. 2, Article ID 24001, 2009.

[5] M. Kadkhodabeigi, "Two dimensional model of melt flows and interface instability in aluminum reduction cells," in Light Metals, vol. 4, pp. 443-448, Wiley, New York, NY, USA, 2008.

[6] V. Bojarevics and K. Pericleous, "Shallow water model for aluminium electrolysis cells with variable top and bottom," in Light Metals, vol. 2, pp. 403-408, 2008.

[7] J. Li, W. Liu, Y. Lai, and Y. Liu, "An improved finite-element model for electromagnetic analysis in aluminum cells," JOM, vol. 60 , no. 2, pp. 58-61, 2008.

[8] M. Li and J. Zhou, "Numerical simulation of busbar configuration in large aluminum electrolysis cell," Journal of Central South University of Technology, vol. 15, no. 2, pp. 271-275, 2008.
[9] V. Bojarevics and K. Pericleous, "Solutions for the metal-bath interface in aluminium electrolysis cells," in Light Metals, pp. 569-574, TMS, 2009.

[10] V. Bojarevics and K. Pericleous, "Time dependent MHD models for aluminium reduction cells," in Jim Evans Honorary Symposium: Proceedings of the Symposium Sponsored by the Light Metals Division of The Minerals, Metals and Materials Society (TMS), pp. 199-206, 2010.

[11] Z. Liu, W. Li, Q. Zhao, J. Zhou, and Y. Wang, "Current efficiency predictive model and its calibration and validation," in Light Metals, pp. 935-938, 2012.

[12] J. Bruggeman, "Technical contributions of late Warren Haupin-a review," in Light Metals, pp. 495-500, 2008.

[13] J. P. Peng, N. X. Feng, Y. L. Jiang, Y. W. Wang, and J. You, “Test of drained aluminum electrolysis cell with $\mathrm{TiB}_{2} / \mathrm{G}$ graphitized cathode at high current density," Chinese Journal of Nonferrous Metals, vol. 18, no. 4, pp. 738-744, 2008 (Chinese).

[14] N. Feng, "Low energy consumption aluminum reduction cell with novel cathodes," China Patent, ZL200710010523.4, 2007.

[15] B. E. Launder and D. B. Spalding, "The numerical computation of turbulent flows," Computer Methods in Applied Mechanics and Engineering, vol. 3, no. 2, pp. 269-289, 1974.

[16] D. S. Severo, V. Gusberti, A. F. Schneider, E. C. V. Pinto, and V. Potocnik, "Comparison of various methods for modeling the metal-bath interface," in Light Metals, pp. 413-418, 2008. 

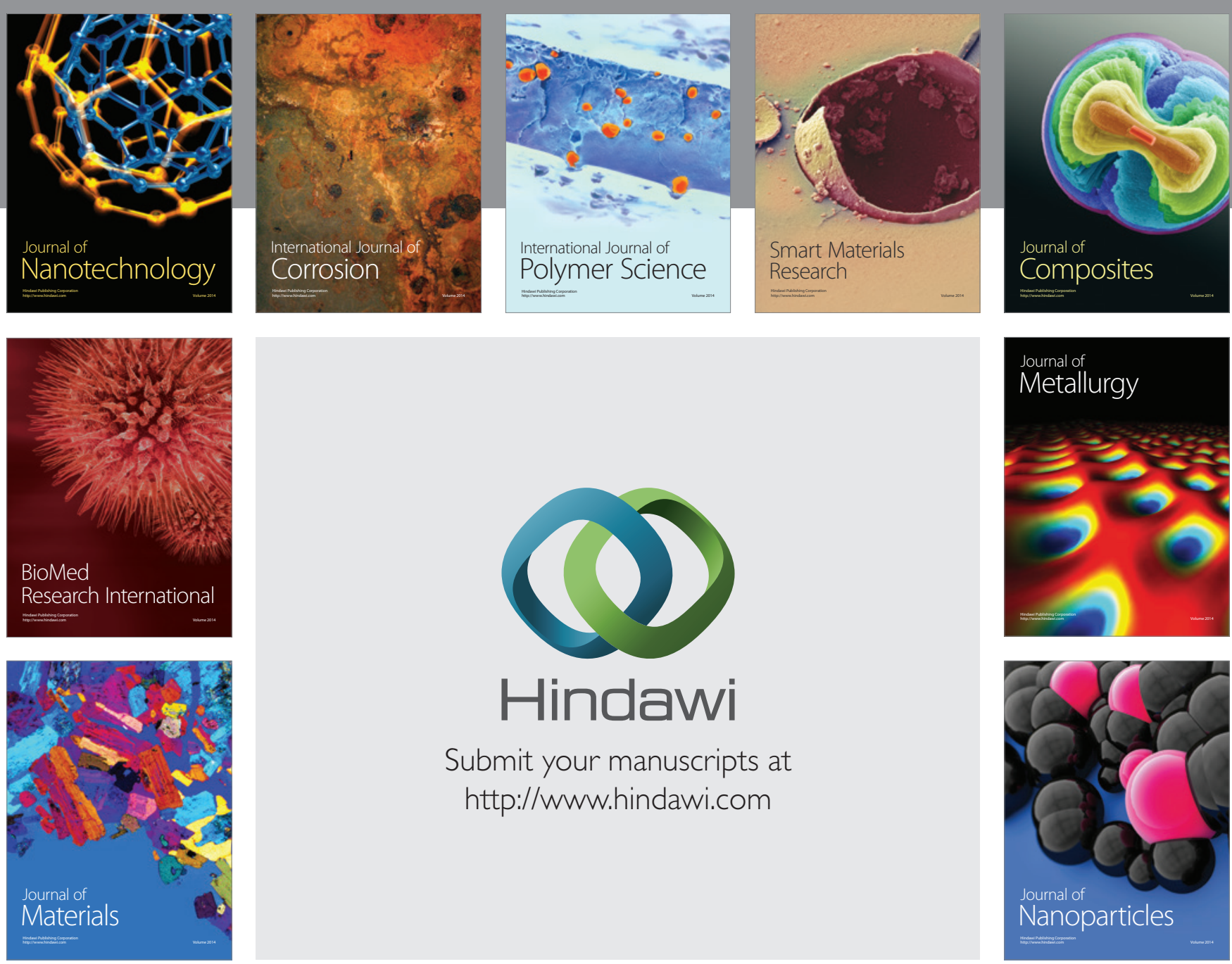

Submit your manuscripts at http://www.hindawi.com
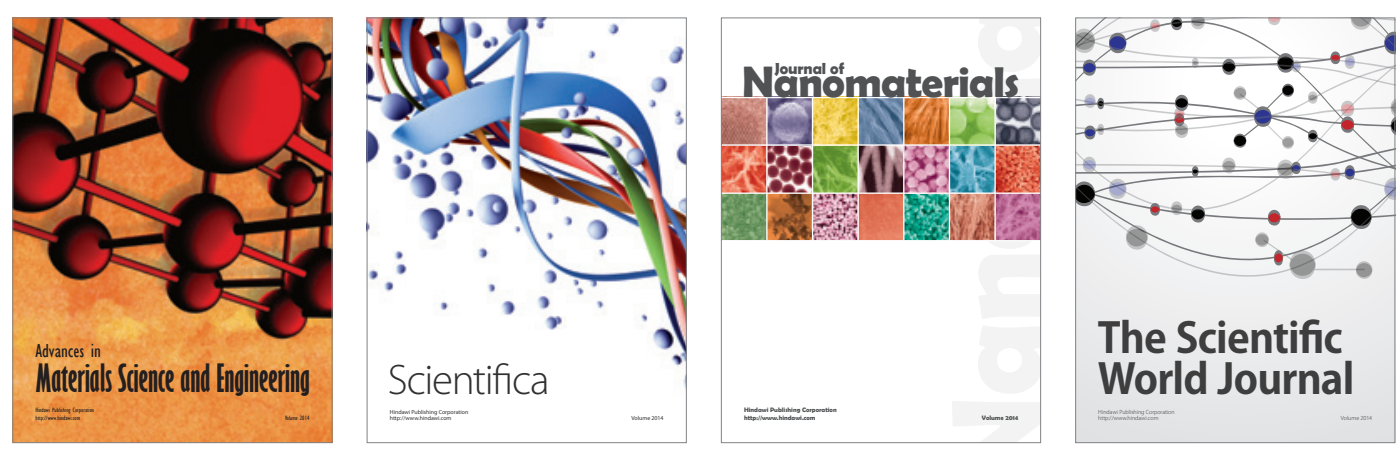

\section{The Scientific World Journal}
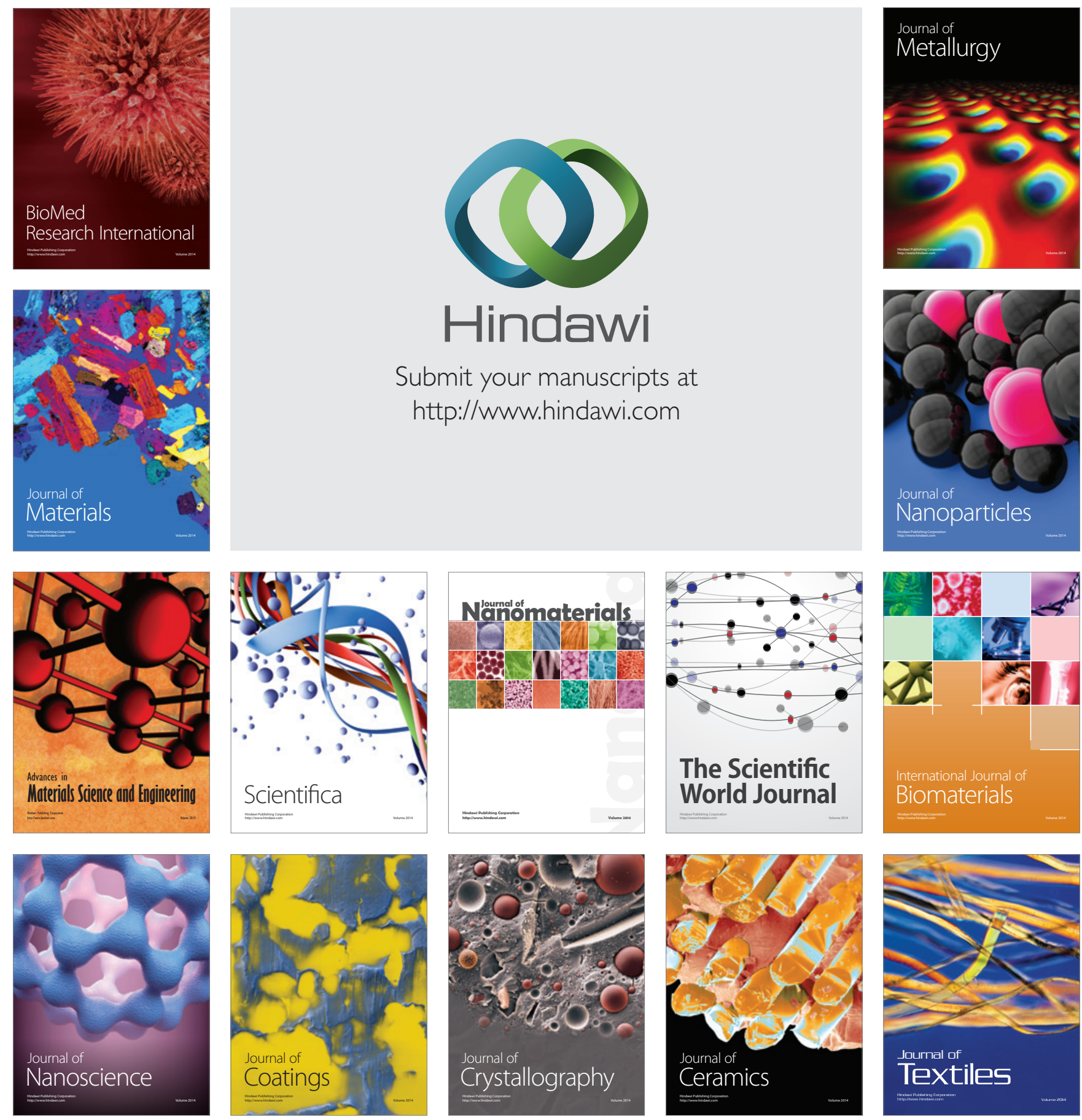